\title{
Orbital solitary fibrous tumor: a clinicopathologic study from a Chinese tertiary hospital with a literature review
}

This article was published in the following Dove Press journal: Cancer Management and Research

\author{
Jianqin Shen' \\ Huiyan $\mathrm{Li}^{\prime}$ \\ Shi Feng ${ }^{2}$ \\ Hongguang Cui' \\ 'Department of Ophthalmology, \\ ${ }^{2}$ Department of Pathology, The \\ First Affiliated Hospital, College \\ of Medicine, Zhejiang University, \\ Hangzhou, People's Republic of China
}

Correspondence: Hongguang Cui Department of Ophthalmology, The First Affiliated Hospital, College of Medicine, Zhejiang University, No. 79 Qingchun Road, Hangzhou 310003, Zhejiang Province, People's Republic of China Tel +86 57I 87236790

Email II89002@zju.edu.cn
Purpose: To report the clinical features, imaging manifestations, histopathology, and immunohistochemical features of several cases of orbital solitary fibrous tumors (SFTs) in a Chinese tertiary hospital, and to undertake a literature review of this rare disease.

Methods: A non-comparative retrospective review of clinical presentations, imaging manifestations, histopathology, and immunohistochemical features as well as the management and disease outcomes of patients with orbital SFT was conducted along with a review of orbital SFT cases in the literature.

Results: This study includes two male and two female patients, with an average age of 53 years. Common presentations among these patients included a palpable subcutaneous mass, swelling of the eyelid, proptosis, diplopia, and vision disturbance. Three patients (cases 2-4) underwent imaging scans. All patients had complete surgical excisions and the tissue was subjected to pathological analysis. One patient (Case 4) experienced a recurrence with malignant transformation and received a re-excision surgery and postoperative radiotherapy. All patients remain alive and well after a minimum follow-up of 12 months (range 12-34 months).

Conclusion: Despite its rare occurrence, we suggest that the possibility of orbital SFTs needs to be considered when a painless, slowly growing orbital mass is identified. Typical characteristic magnetic resonance imaging features of orbital SFTs are iso- or hypointense signals on T1 and T2-weighted images, with marked enhancement. A positive cluster of differentiation 34 (CD34) staining is an important diagnostic clue favoring SFT. Some orbital SFTs are infiltrating, aggressive, or recur with malignant transformation. Therefore, regular long-term follow-up after complete excision is mandatory.

Keywords: orbit, CD34, malignant transformation, MR

\section{Introduction}

The solitary fibrous tumor (SFT) is a rare spindle cell tumor originating from the mesenchyme and was first described in pleural tissue in $1931 .{ }^{1}$ A recent study has reported that SFT is found in extrapleural locations such as lung, liver, pericardium, peritoneum, mediastinum, nasal cavities, thyroid, parotid gland, and the orbit. ${ }^{2}$ SFT in the orbit is extremely rare. Since the first report of an orbital SFT in $1994,,^{3,4}$ only 90 cases have been described in the English literature to date. ${ }^{5-15}$ Most orbital SFTs are described as isolated case reports. Herein, we present four orbital SFT cases and conduct a review of the literature discussing the presentation, imaging, histopathology, management, and outcomes of this rare disease. 


\section{Methods}

\section{Clinical data}

A non-comparative retrospective review was conducted for patients presenting to our hospital with a pathological diagnosis of orbital SFT between 2014 and 2017. The study was approved by the Human Subjects Ethics Subcommittee of the First Affiliated Hospital of Zhejiang University, and it adhered to the tenets of the Declaration of Helsinki. Written informed consent for the publication of case details was obtained from all patients in our study. Simultaneously, a review of the literature was done using PubMed to search combinations of the terms "orbital solitary fibrous tumor."

\section{Histopathology and immunohistochemistry}

Surgical samples were collected and embedded in paraffin for histological and immunohistochemical analyses. Immunohistochemical studies for cluster of differentiation 34 (CD34), cluster of differentiation 99 (CD99), B-cell lymphoma 2 (Bcl-2), smooth muscle actin (SMA), S-100 protein, Ki-67, cytokeratin (CK), Desmin, and cluster of differentiation 117 (CD117) were undertaken on paraffin sections in all samples. All antibodies were obtained from OriGene (Rockville, MD, USA).

\section{Results \\ Case I}

A 37-year-old woman was referred to our department with a complaint of swelling in the right lower eyelid for 4 years. A focal, firm, nontender swelling with well-defined margins was palpated in the inferomedial side of her right orbit.

The mass was completely excised via a subciliary approach. Gross examination of the surgical specimen disclosed a well-encapsulated $25 \times 20 \mathrm{~mm}$ oval mass. On histopathological study, the tumor was composed of haphazardly arranged spindle cells with bland nuclei and inconspicuous nucleoli (Figure 1). Immunohistochemical analysis showed that the tumor cells exhibited diffuse immunoreactivity for CD34 and CD99 and was approximately 5\% positive for Ki-67 (Table 1). These observations were consistent with the diagnosis of SFT.

This patient is still alive and well, without local relapse after 27 months.

\section{Case 2}

A 51-year-old man came to our department with a palpable subcutaneous mass in the right lacrimal sac area which was first noticed 6 months earlier. Findings on ophthalmic examination were normal, except for a movable mass without tenderness.

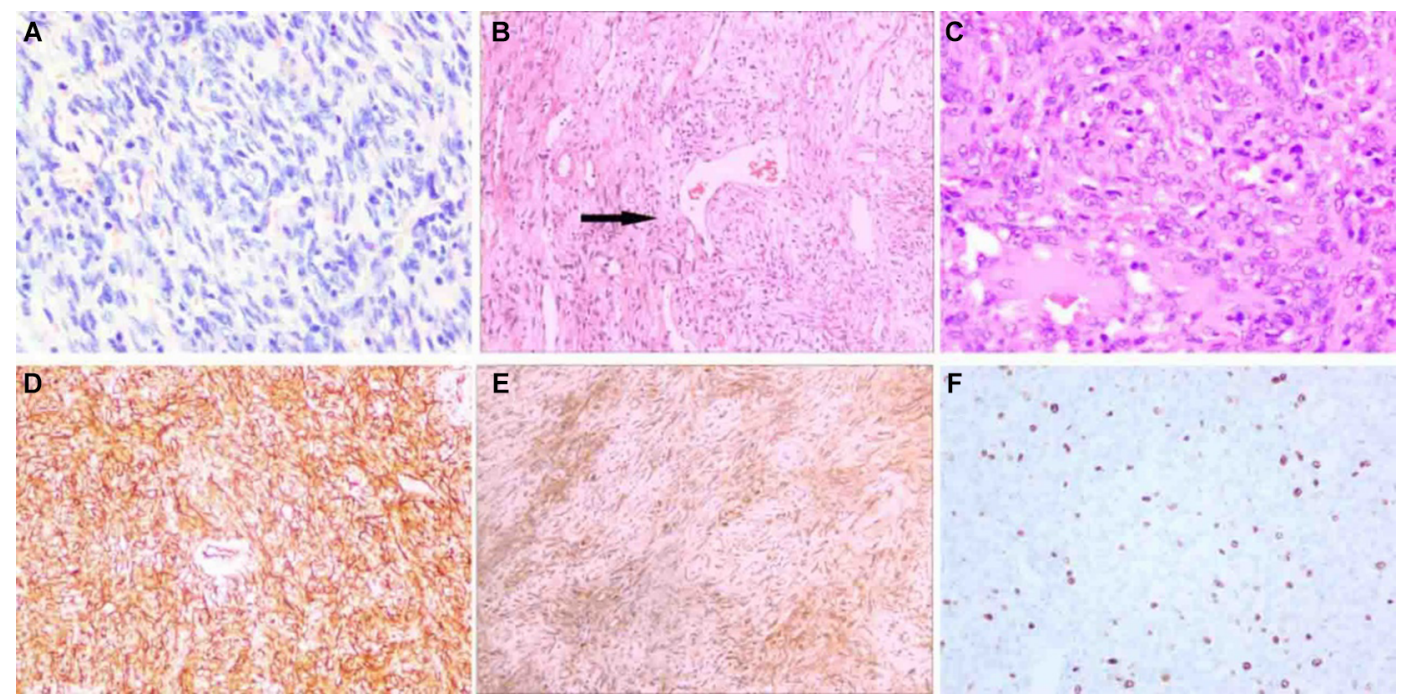

Figure I Histopathological and immunohistochemical staining of tumors in our cases.

Notes: (A) The tumor is composed of haphazardly arranged spindle cells with bland nuclei and inconspicuous nucleoli. (Case I; HE staining; original magnification: $\times 200$ ). (B) Variably collagenous and numerous endothelium-lined vascular channels are noted. (Case 2; arrow shows an occasional vascular channel with a staghorn appearance; HE staining; original magnification: $\times 200$ ). (C) Tumor cells with oval nuclei, conspicuous nucleoli, and mitotic figure are noted. (recurrent sample of Case 4; HE staining; original magnification: $\times 200$ ). (D) Tumor cells are positive for CD34. (recurrent sample of Case 4; original magnification: $\times 200)$. (E) The tumor cells are positive for Bcl-2 (Case 2; original magnification: $\times 200)$. (F) The tumor cells are positive for $\mathrm{Ki}-67(>10 \%)$, which indicates malignant transformation (recurrent sample of Case 4; original magnification: $\times 200$ ).

Abbreviations: HE, hematoxylin and eosin; CD34, cluster of differentiation 34; Bcl-2, B-cell lymphoma 2. 
Orbital magnetic resonance (MR) imaging showed an approximately $20 \times 15 \mathrm{~mm}$, well-circumscribed circular tumor in the subcutaneous region of the right lacrimal sac area, presenting with slight low signal intensity on $\mathrm{T} 1$ and $\mathrm{T} 2$ images, heterogeneous intermediate signal intensity on fatsuppression images, and diffusely heterogeneous enhancement after intravenous gadolinium administration (Figure 2).

The mass was completely removed via a medial canthus split approach. Histopathologically, the tumor was composed of spindle cells and the stroma was variably collagenous. The tumor showed numerous endothelium-lined vascular channels, some of which showed an occasional staghorn appearance (Figure 1). Immunohistological study showed positivity for CD34 and Bcl-2, and weak positivity for Ki-67 $(<5 \%$; Table 1 and Figure 1). These findings support the diagnosis of SFT.

This patient is alive and has kept well for 34 months.

\section{Case 3}

A 65-year-old woman was referred to our department, and presented with a 1-year history of a painless, palpable nasal mass in the left orbit. A $20 \times 15 \mathrm{~mm}$, well-circumscribed mass

Table I Summary of the histological features of orbital SFT in the present series

\begin{tabular}{|c|c|c|c|c|c|c|c|c|c|}
\hline Case No. & CD34 & CD99 & Bcl-2 & SMA & S- 100 & CK & Desmin & CDII7 & Ki-67 \\
\hline Case I & + & + & - & - & - & - & - & - & $+(5 \%)$ \\
\hline Case 2 & + & - & + & - & - & - & - & - & $+(<5 \%)$ \\
\hline Case 3 & + & - & - & - & - & - & - & - & $+(<5 \%)$ \\
\hline Case 4 & + & - & - & - & - & - & - & - & $+(<5 \%)$ \\
\hline 2nd operation & + & - & - & - & - & - & - & - & $+(>10 \%)$ \\
\hline
\end{tabular}

Abbreviations: CD, cluster of differentiation; Bcl-2, B-cell lymphoma 2; SMA, smooth muscle actin; CK, cytokeratin; +, positive; -, negative.
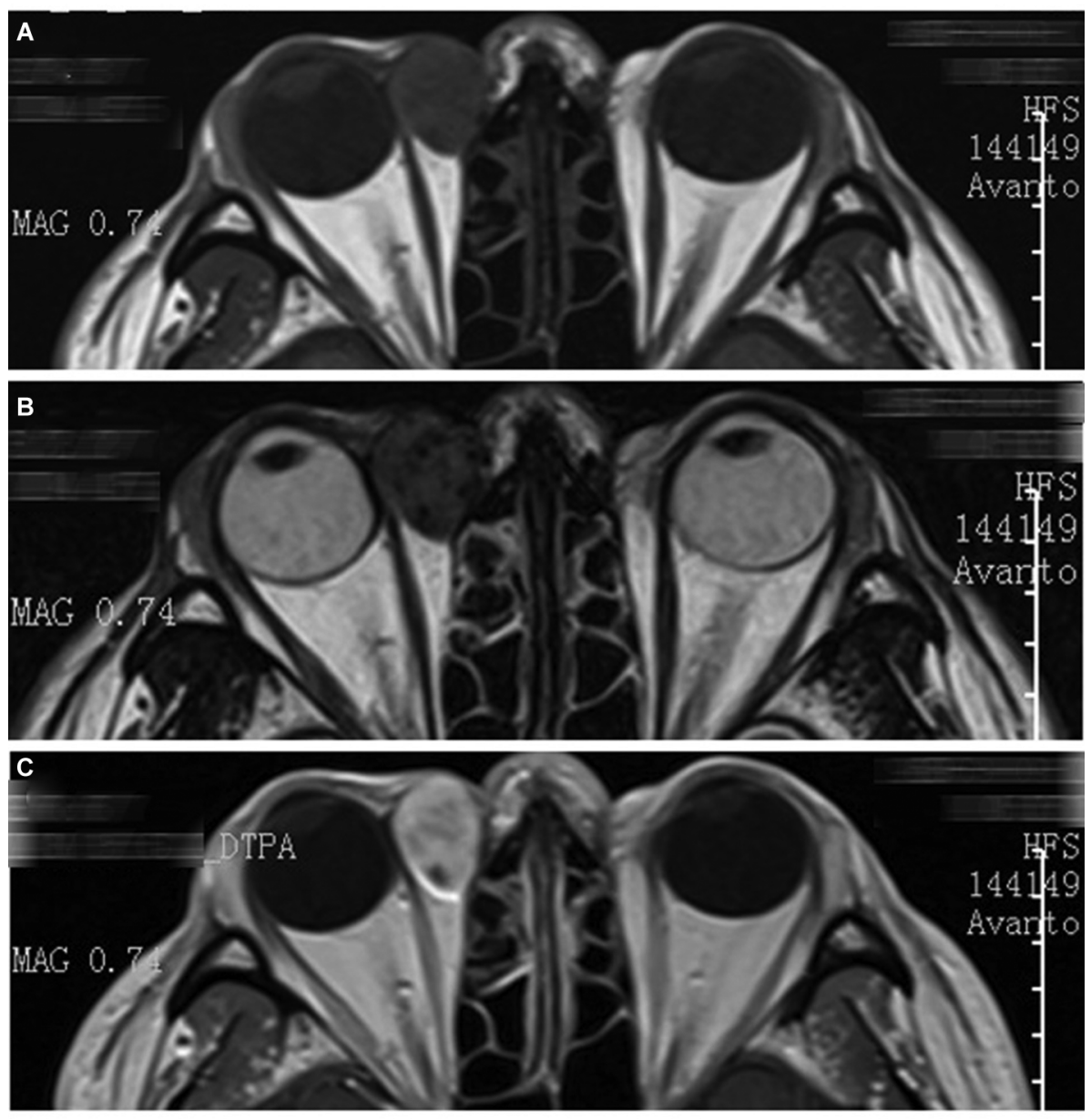

Figure 2 MR scan of Case 2 shows a well-circumscribed circular mass in the subcutaneous region of the right lacrimal sac area.

Notes: (A) TI image, (B) T2 image, and (C) post-contrast TI image.

Abbreviation: MR, magnetic resonance. 
was palpated in the nasal region of the left upper lid, and the rest of the ophthalmic examination was unremarkable.

Orbital MR imaging revealed a well-circumscribed, $20 \times 15 \mathrm{~mm}$ subcutaneous mass in the superomedial side of her left orbit, with homogeneous isointense signals on T1 images and hypointense signals on T2 images. The lesion showed strong gadolinium enhancement (Figure 3).

Complete removal of the lesion was undertaken via an upper eyelid medial split approach. The mass was approximately $22 \times 17 \times 15 \mathrm{~mm}$ in size. Histopathological examination revealed the tumor was composed of uniform spindle cells containing fusiform nuclei, indistinct nucleoli, and a pale eosinophilic cytoplasm in a collagenous matrix. Small- to medium-sized endothelium-lined vascular channels were diffusely scattered. Moreover, immunohistochemistry showed strong positivity for CD34 staining and weak positivity for Ki-67 staining $(<5 \%)$, consistent with a diagnosis of SFT (Table 1).

The patient is alive and healthy, without local relapse for at least 26 months.

\section{Case 4}

A 60-year-old man was referred to our department with complaints of proptosis and diplopia in his left eye for 2 months. He had a history of hepatocellular carcinoma and had undergone a transcatheter arterial chemoembolization operation 2 years before this presentation.

Ophthalmic examination showed an 8-mm proptosis, diffuse conjunctival congestion, and chemosis of his left eye as well as limitation of extraocular movement in all gazes. The visual acuity of the left eye had decreased to $1 / 20$, and could not be corrected. A fundus examination showed papilloedema and venous congestion.

The orbital MR showed a giant, well-circumscribed mass in the muscle cone of the left orbit that could not be separated from the optic nerve and pushed the optic nerve to the nasal side. The lesion had two types of imaging features on MR. One presented with low signal intensity on T1 and T2 images, and the other presented with isointense signal intensity on $\mathrm{T} 1$ and $\mathrm{T} 2$ images. The latter presented a diffusely
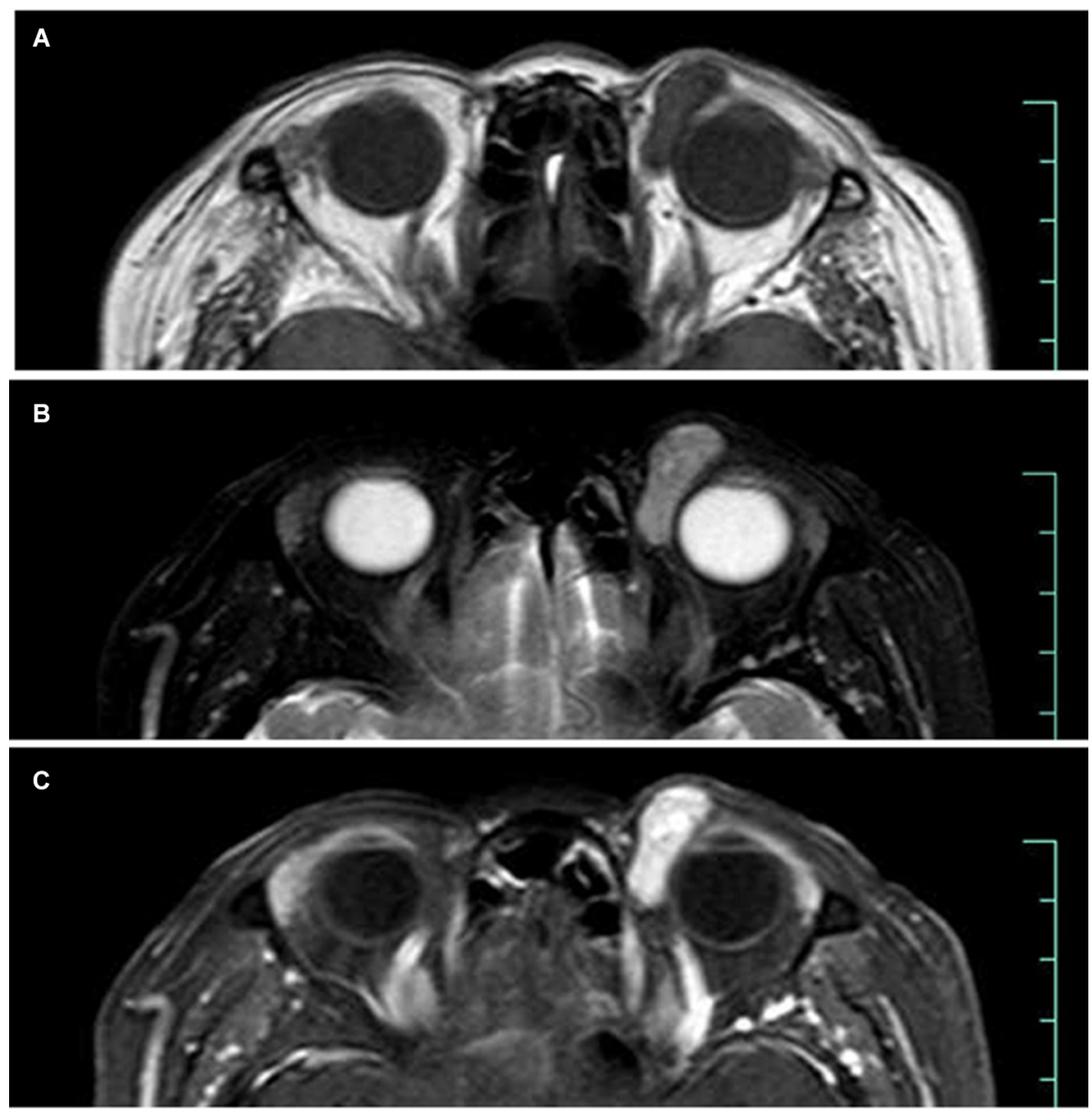

Figure 3 MR scan of Case 3 shows a well-circumscribed subcutaneous mass in the superomedial side of her left orbit with homogeneous isointense signal on TI images and hypointense signal on $\mathrm{T} 2$ images.

Notes: (A) TI image, (B) T2 image, and (C) post-contrast TI image. 
heterogeneous enhancement after intravenous administration of gadolinium (Figure 4).

The tumor was removed by lateral orbitotomy. A part of the mass was grayish white with a size of $18 \times 15 \times 15 \mathrm{~mm}$, whereas the rest of the mass was wine-red with a size of $3.0 \times 2.5 \times 2.5 \mathrm{~mm}$. Histopathological study revealed haphazardly arranged spindle cells with dense collagenous fibrosis. No mitoses or areas of necrosis were identified. The tumor contained numerous blood vessels, ranging from capillary to medium-sized vessels. Immunohistochemistry showed strong positivity for CD34 staining and weak positivity for Ki-67 staining $(<5 \%)$, which confirmed our diagnosis of SFT (Table 1).

The mass recurred 14 months after the operation. Orbital MR imaging revealed a well-circumscribed $37 \times 34 \times 23 \mathrm{~mm}$ mass in the muscle cone of the left orbit with isointense signal intensity on T1 images, and isointense to slight hyperintense signal intensity on T2 images. A post-contrast T1-weighted image revealed a heterogeneous enhancement of the lesion (Figure 5).

An extensive resection was done. Preoperatively, the recurrent mass was identified in the muscle cone and was found to be adherent to the optic nerve. Gross examination revealed the tumor was grayish white with a size of $35 \times 30 \times 25 \mathrm{~mm}$. Histopathologically, the tumor was composed of spindle cells, a section of which had oval nuclei and conspicuous nucleoli. Mitotic figures were noted, with a transition into a high-grade component (Figure 1). Moreover, these tumor cells showed strong and diffuse positivity for CD34 staining and $>10 \%$ cells were positive on $\mathrm{Ki}-67$ staining, suggesting malignant degeneration of the tumor (Table 1 and Figure 1).

The patient was referred to the department of radiation oncology for radiotherapy. There was no evidence of recurrence during a 12-month follow-up period.

\section{Discussion}

The SFT, first identified by Klemperer and Rabin in 1931, is a rare tumor which is described as a mesenchymal neoplasm originating in the pleural structures. ${ }^{1}$ Subsequently, it has also been reported in extrapleural locations, such as the upper airway tract, nasal and paranasal sinuses, parotid and salivary glands, thyroid, lung, mediastinum, pericardium, peritoneum, liver, spine, soft tissues, and orbit. ${ }^{16-21}$ An orbital SFT was first described by Westra et al and Dorfman et al in 1994 ${ }^{3,4}$ and, since then, approximately 90 cases have been reported in ophthalmologic and pathologic journals. ${ }^{5-15}$

\section{Clinical features}

Orbital SFT has been documented across a wide age range from 9 to 76 years, predominating in the fifth decade, with no sex predilection according to previous reports. ${ }^{22-25}$ In this study, the four cases described include two men and two women, with a mean age of 53 (range 37-65 years), which was consistent with previous reports (Table 2).

In a study reported by Romer et al, 25 cases were identified in the left orbit and 14 in the right orbit. ${ }^{26}$ In our study,
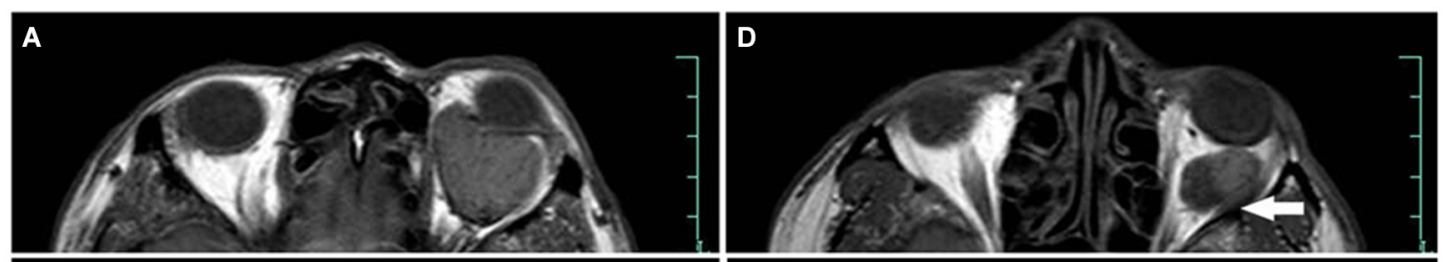

B
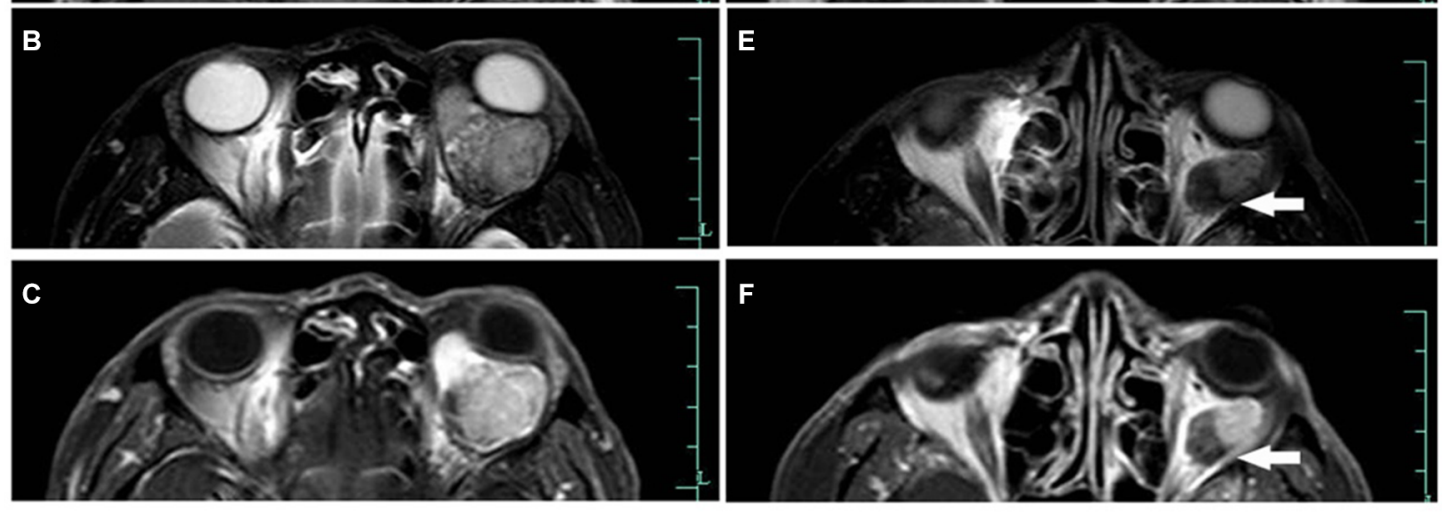

Figure 4 The MR scan of Case 4 (Ist op). Arrows show the lesion had two types of imaging features on MRI. The medial part of the mass indicates a tissue with high collagen content whereas the lateral part indicates a tissue with hypervascular content.

Notes: (A, D) T1 image, (B, E) T2 image, and (C, F) post-contrast TI image. Abbreviation: op, operation. 

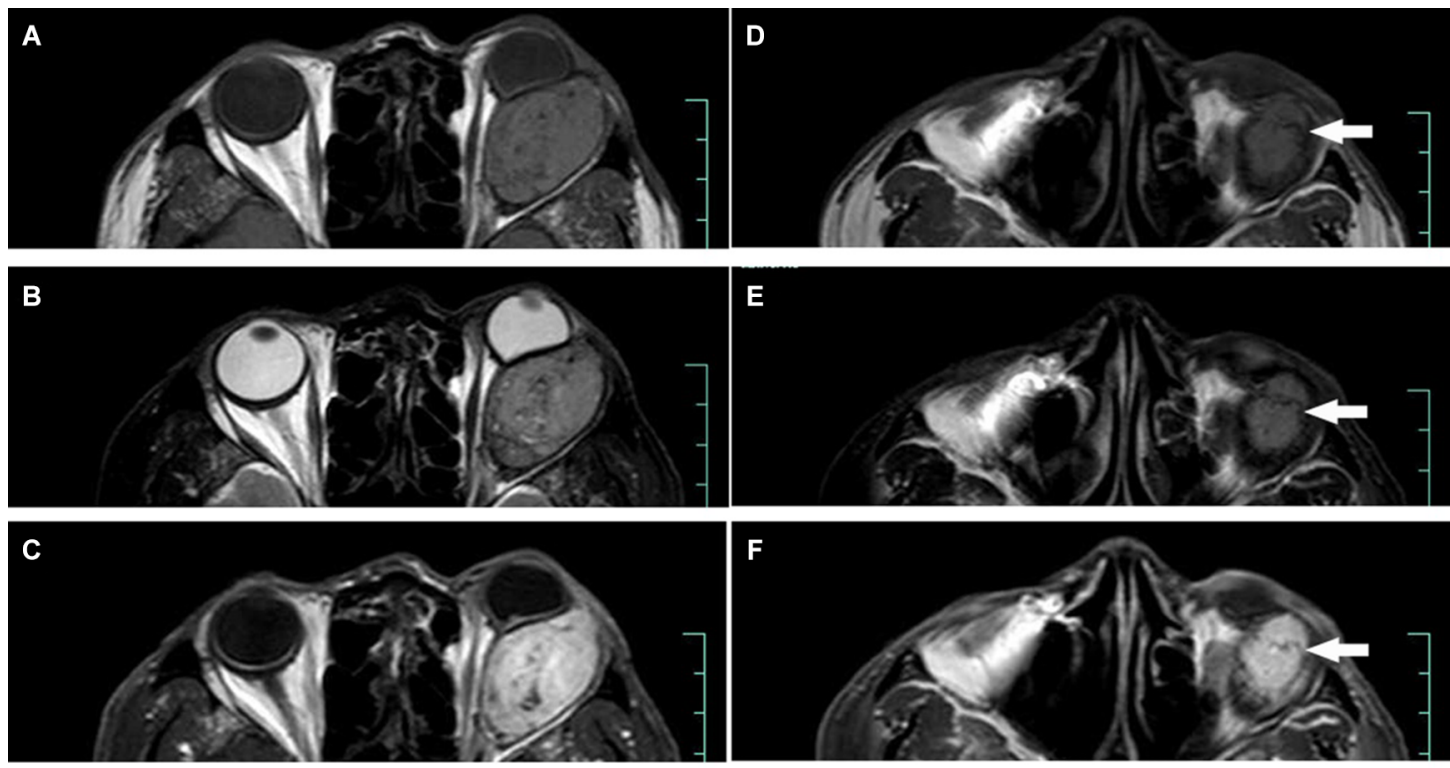

Figure 5 MR scan of Case 4 (2nd operation). Arrows show signal tubular structures, which might represent fast-flow vessels within the tumor. Notes: (A, D) TI image, (B, E) T2 image, and (C, F) post-contrast TI image.

Table 2 Summary of clinical features of orbital SFT in the present series

\begin{tabular}{|c|c|c|c|c|c|c|c|c|c|c|}
\hline $\begin{array}{l}\text { Case } \\
\text { No. }\end{array}$ & $\begin{array}{l}\text { Age } \\
\text { (yrs) }\end{array}$ & Gender & $\begin{array}{l}\text { Affected } \\
\text { side }\end{array}$ & Location & $\begin{array}{l}\text { Main clinical } \\
\text { presentation }\end{array}$ & $\begin{array}{l}\text { Clinical } \\
\text { history }\end{array}$ & Treatment & $\begin{array}{l}\text { Time of } \\
\text { recurrence } \\
\text { (mo) }\end{array}$ & $\begin{array}{l}\text { Follow-up } \\
\text { (mo) }\end{array}$ & Status \\
\hline I & 37 & $F$ & $\mathrm{R}$ & Lower eyelid & $\begin{array}{l}\text { A palpable } \\
\text { subcutaneous mass }\end{array}$ & $4 \mathrm{yrs}$ & Total excision & - & 27 & Alive \\
\hline 2 & 51 & $M$ & $R$ & Lacrimal area & $\begin{array}{l}\text { A palpable } \\
\text { subcutaneous mass }\end{array}$ & $6 \mathrm{mos}$ & Total excision & - & 34 & Alive \\
\hline 3 & 65 & $\mathrm{~F}$ & L & $\begin{array}{l}\text { Superomedial } \\
\text { orbital } \\
\text { quadrant }\end{array}$ & $\begin{array}{l}\text { A palpable } \\
\text { subcutaneous mass }\end{array}$ & $\mathrm{l} y \mathrm{r}$ & Total excision & - & 26 & Alive \\
\hline 4 & 60 & M & L & $\begin{array}{l}\text { In the muscle } \\
\text { cone }\end{array}$ & $\begin{array}{l}\text { Proptosis, vision } \\
\text { disturbance }\end{array}$ & $2 \mathrm{mos}$ & Total excision & 14 & 14 & $\begin{array}{l}\text { Alive with } \\
\text { relapse }\end{array}$ \\
\hline $\begin{array}{l}\text { 2nd } \\
\text { operation }\end{array}$ & 60 & M & L & $\begin{array}{l}\text { Local } \\
\text { recurrence }\end{array}$ & $\begin{array}{l}\text { Proptosis, vision } \\
\text { disturbance }\end{array}$ & - & Total excision & - & 12 & Alive \\
\hline
\end{tabular}

Abbreviations: F, female; M, male; R, right; L, left; yr, years; mos, months; -, not applicable.

two cases were found in the right orbit and two in the left (Table 2).

According to the reviews from Le et al, orbital SFTs may occur in a variety of areas in the orbital space: $20 \%$ in the superomedial orbital quadrant, $15 \%$ in the medial orbit, $13 \%$ in the superotemporal area, $9.5 \%$ in the lacrimal area, and $7 \%$ in the inferotemporal area. ${ }^{5}$ In our study, the tumor in Case 1 was in the lower eyelid, and in the lacrimal sac area in Case 2. Tumors in cases 3 and 4 were located in the superomedial orbital quadrant and muscle cone, respectively.

Orbital SFT commonly presents as a slowly progressive, unilateral, painless proptosis and may be associated with eyelid swelling, vision disturbances, a palpable mass, tearing, and ptosis. In the present study, a palpable subcutaneous mass was the most frequent initial feature. Proptosis and vision disturbances were observed in Case 4 (Table 2). Orbital SFTs were less commonly associated with optic nerve dysfunction and extraocular muscle impairment depending on their size and location. ${ }^{5}$

\section{MR imaging presentation}

On imaging, an orbital SFT presents as well-defined soft tissue masses with heterogeneously or homogeneously strong enhancement on computed tomography (CT) and MR images. ${ }^{27}$ Furthermore, internal calcifications and necrosis have been reported occasionally. ${ }^{16,17}$ Compared with the cerebral cortex or extraocular muscle, the signal intensity of SFTs seen on MR images, in general, were isointense on T1-weighted 
images and isointense to hypointense on T2-weighted images. Sometimes, a hypointense signal intensity can be seen within the lesion on both T1- and T2-weighted images, reflecting fibrous tissue with high collagen content. ${ }^{19,23,26,28-32}$ Moreover, a hyperintense signal can be observed within the lesion on T2-weighted images in some cases, causing signal intensity heterogeneity on T2-weighted images. These T2 hyperintense signals are related to internal hemorrhage, cystic degeneration, or relatively fresh fibrosis. ${ }^{19,32,33}$ Variations of the signal intensity on MR images reflected the differences of cellular components, collagen, fibroblasts, and degenerative change contained within individual tumors.

Homogeneous or heterogeneously attenuated enhancement is reported to be the most prominent feature of SFT that is revealed with $\mathrm{CT}$ and MR imaging, which is attributed to the prominent vascular channels within the tumor. ${ }^{19,23,31,34-37}$ Of the three lesions examined by MR in this study, one showed homogeneously marked enhancement (Case 3), and the rest showed heterogeneously marked enhancement (Cases 2 and 4). On the MR scan of Case 4, signal-intensity tubular structures were noted on T1, T2, and post-contrast T1-weighted MR images, which might represent fast-flow vessels within the tumor (Figure 5).

\section{Histopathologic and immunohistochemical features}

As clinical signs and radiological features are not distinctive, histological examination plays an important role in the diagnosis of orbital SFT. Tumors appeared as regular round masses, of hard consistency, and were homogeneously grayish white upon sectioning. All tumors in the present study were firm; neither cystic spaces nor necrosis were found. Tumors in cases 1, 2, and 3 were grayish white in color, whereas the mass in Case 4 was wine-red. Histological study revealed alternating cellular and hypocellular areas with spindle-shaped cells presenting an ovoid and irregular nucleus, inconspicuous nucleoli, and a scant, undefined eosinophilic cytoplasm. ${ }^{38}$ Spindle-shaped cells grow in a haphazard manner in a variable cellular stroma, which is described as a "patternless pattern" or keloid-like hyalinization. The tumor showed thick bands of collagen interspersed between the tumor cells, branching thin-walled vessels of varying caliber, and a "staghorn" vascular pattern, similar to a hemangiopericytoma (HPC). These features are consistent with those observed in our cases.

Microscopic features alone are insufficient to validate SFT. The key to identify SFT is to conduct immunohistological analysis. ${ }^{25,39}$ Strong and consistent positivity of CD34 is an important diagnostic marker of SFT, which demonstrates strong CD34 reactivity in $90-100 \%$ of cases, ${ }^{2,3}$ and the expression of CD34 may be lost in tumors that undergo malignant transformation. ${ }^{40}$ Meanwhile, SFT has been documented to exhibit strong and diffuse positivity with vimentin, CD99, and Bcl-2. ${ }^{38}$ Epithelial membrane antigen (EMA) and SMA might occasionally be detected, whereas SFT is usually negative for S-100 and CK. ${ }^{41}$

Due to its histological similarities to other spindle-shaped cell tumors, SFT has been confused histologically with other lesions, such as HPC, fibrous histiocytoma, schwannoma, and meningioma. HPC displays a mixture of spindle-shaped tumor cells with oval nuclei and a small cytoplasm mixed with a network of thin-walled blood vessels or sinusoid-like spaces. HPC cells show high reactivity to the CD34 antibody and vimentin, but lack immunoreactivity to EMA. ${ }^{42}$ Fibrous histiocytoma usually consists of fibroblasts and prominent round histiocytic cells in a characteristic storiform pattern. Immunohistochemical staining consistently reveals that histiocytes are CD68 positive but are usually CD34 negative. Schwannomas display a characteristic morphology of alternating Antoni A and Antoni B areas and Verocay bodies. Immunohistochemical staining shows strong reactivity to neural markers such as $\mathrm{S}-100$ protein, which is negative in a SFT. ${ }^{23}$ Fibrous meningioma often shows characteristic psammoma bodies, which are absent in SFTs. Besides, compared to SFT, a fibrous meningioma is usually better stained by an EMA antibody, but only mildly or focally positive on CD34 and Bcl-2 staining. ${ }^{43}$

\section{Malignant transformation and aggressive behavior}

Most orbital SFTs are described in isolated case reports; thus their clinical behavior is currently unknown. It is generally believed that SFTs behave in a benign fashion and follow a non-aggressive course.

A few of the orbital SFT cases reported have displayed malignant histological features, defined by hypercellularity, pleomorphism, increased tumor size $(\geq 5 \mathrm{~cm})$, mitotic counts $>4$ per 10 high-power fields, and necrosis. ${ }^{29,38,44-47}$ Immunohistochemically, the expression of CD34 may be lost in tumors that undergo malignant transformation in cases of orbital SFTs. ${ }^{40,45}$ However, these pathologic factors do not always correlate with the clinical behavior of the tumor. Our literature search reviewed that only two of the five documented malignant orbital SFTs cases exhibited aggressive behavior, one of which had a recurrence whereas the other one

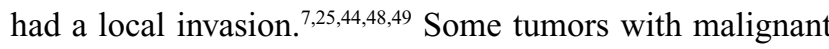


Table 3 Summary of reported recurrent orbital SFT with malignant transformation

\begin{tabular}{|c|c|c|c|c|c|c|c|c|}
\hline Source, year & Age & Gender & $\begin{array}{l}\text { Affected } \\
\text { side }\end{array}$ & Initial diagnosis & $\begin{array}{l}\text { Initial } \\
\text { treatment }\end{array}$ & $\begin{array}{l}\text { Times of } \\
\text { recurrence }\end{array}$ & Final diagnosis & $\begin{array}{l}\text { Final } \\
\text { treatment }\end{array}$ \\
\hline Carrera et $\mathrm{al}^{45}$ & 64 & $M$ & $\mathrm{~L}$ & SFT & Total excision & 4 & Malignant SFT & Re-excision \\
\hline $\begin{array}{l}\text { Manousaridis } \\
\text { et } \mathrm{al}^{60}\end{array}$ & 53 & $\mathrm{~F}$ & $\mathrm{R}$ & $\begin{array}{l}\text { SFT with focal } \\
\text { malignant } \\
\text { transformation }\end{array}$ & Total excision & I & Malignant SFT & $\begin{array}{l}\text { Re-excision + } \\
\text { radiotherapy }\end{array}$ \\
\hline Wang et $\mathrm{al}^{61}$ & 38 & $M$ & $\mathrm{R}$ & SFT & Total excision & 2 & Malignant SFT & $\begin{array}{l}\text { Re-excision + } \\
\text { radiotherapy }\end{array}$ \\
\hline $\begin{array}{l}\text { Blandamura } \\
\text { et } \mathrm{al}^{62}\end{array}$ & 75 & NM & $\mathrm{R}$ & SFT & $\begin{array}{l}\text { Excision+ } \\
\text { radiotherapy }\end{array}$ & I & $\begin{array}{l}\text { SFT with focal } \\
\text { malignant } \\
\text { transformation }\end{array}$ & Re-excision \\
\hline $\begin{array}{l}\text { Case } 4 \text { in the } \\
\text { present study }\end{array}$ & 60 & $M$ & $\mathrm{~L}$ & SFT & Total excision & I & Malignant SFT & $\begin{array}{l}\text { Re-excision }+ \\
\text { radiotherapy }\end{array}$ \\
\hline
\end{tabular}

Abbreviations: F, female; M, male; R, right; L, left; NM, not mentioned; SFT, solitary fibrous tumor.

histologic findings remained indolent, whereas other tumors with completely benign histologic findings behaved aggressively. The aggressive behavior of orbital SFTs is defined by a local invasion, recurrence, and distant metastases. ${ }^{7,29,44,46,50-54}$ Nineteen of the 21 recurrent orbital SFTs were histologically benign. Young and Hardy reported a histologically benign orbital SFT case that invaded intracranial tissues. ${ }^{54}$

Malignant transformation of a recurrent SFT has been described in lung, pleura, and thigh SFT cases. ${ }^{55-57} \mathrm{~A}$ malignant variant of a recurrent orbital SFT has been reported only in four cases, to our knowledge (Table 3 ). The intervals of malignant evolution varied from 6 months to 9 years after initial tumor excision. ${ }^{44,58-60}$ Here, we report the fifth case (Case 4) of a recurrent orbital SFT with malignant transformation, which showed progressive histological dedifferentiation. Two types of malignant transformation have been reported previously: one is malignant or high-grade transformation from benign, low-grade, or intermediate-grade SFT, and the other is de novo occurrence of a malignant SFT. ${ }^{61}$ Malignant transformation of an SFT may have a worse consequence and need close follow-up.

\section{Treatment and prognosis}

Orbital SFTs are so rare that most published cases were individual case reports without documented extended follow-up; therefore, it is difficult to predict the true clinical course of these tumors.

Radical surgical resection seemed to be the most important prognostic factor. The extent of resection might be the most predictive factor for recurrence. In Chen et al's research, all four patients who underwent gross total removal did not have recurrence, whereas five of the six patients who had subtotal removal had a recurrence with a median recurrence time of 48 months. ${ }^{62}$ However, there are many factors that could prevent total resection, such as location, size, blood loss, and adhesion. Therefore, resecting as much tumor content as possible should be the goal of the treatment. In Case 4, the patient had a recurrence and malignant transformation. Therefore, a complete re-excision of the tumor and postoperative radiation therapy were carried out. Postoperative radiotherapy can be used as an adjuvant therapy when the lesion is not completely removed or in recurrent and malignant cases. Although there has been no sign of recurrence during a 12-month follow-up in this case, the prognosis should be guarded, and long-term follow-up is warranted.

\section{Conclusion}

Orbital SFTs should be suspected when confronting painless, slow-growing orbital masses although it is a rare entity. High CD34 expression is an important diagnostic marker favoring SFT. Some orbital SFTs are infiltrating, aggressive, or recurrent with malignant transformation. We report the fifth case (Case 4) of a recurrent orbital SFT with malignant transformation. Further research with a larger patient pool and extended followup is necessary to verify the clinical outcome of these tumors.

\section{Acknowledgment}

The work was supported by the Medical Health and Technology Project of Zhejiang Province (grant no. 201796807). The funding organization had no role in the design or conduct of this research.

\section{Disclosure}

The authors report no conflicts of interest in this work.

\section{References}

1. Klemperer P, Rabin CB. Primary neoplasms of the pleura: a report of five cases. Arch Pathol. 1931;11(3):387-414.

2. Brunnemann RB, Ro JY, Ordonez NG, Mooney J, El-Naggar AK, Ayala AG. Extrapleural solitary fibrous tumor: a clinicopathologic study of 24 cases. Mod Pathol. 1999;12(11):1034-1042. 
3. Westra WH, Gerald WL, Rosai J. Solitary fibrous tumor. Consistent CD34 immunoreactivity and occurrence in the orbit. Am J Surg Pathol. 1994;18(10):992-998.

4. Dorfman DM, To K, Dickersin GR, Rosenberg AE, Pilch BZ. Solitary fibrous tumor of the orbit. Am J Surg Pathol. 1994;18(3):281-287.

5. Le CP, Jones S, Valenzuela AA. Orbital solitary fibrous tumor: a case series with review of the literature. Orbit. 2014;33(2):145-151.

6. Hashemi N, Ling JD, Soparkar C, et al. Transarterial Onyx embolization of an orbital solitary fibrous tumor. Ocul Oncol Pathol. 2015;1(2): 98-102.

7. Tenekeci G, Sari A, Vayisoglu Y, Serin O. Giant solitary fibrous tumor of orbit. J Craniofac Surg. 2015;26(5):e390-e392.

8. Genc A, Toktas Z, Azman C, Bozkurt SU, Kilic T. Solitary fibrous tumor of the orbit: a case report and review of the literature. Turk Neurosurg. 2015;25(6):984-987.

9. Gupta S, Verma R, Sen R, Singh I, Marwah N, Kohli R. Solitary fibrous tumor of the orbit. Asian J Neurosurg. 2016;11(1):78.

10. Tata A, Cohen-Inbar O, Sheehan JP. Treatment of orbital solitary fibrous tumour with gamma knife radiosurgery and systematic review of literature. BMJ Case Rep. 2016;2016:bcr2016217114.

11. Tanaka K, Yano H, Hayashi H, Hirano A. Total resection combined with osteotomy is more effective for orbital solitary fibrous tumor excision: a report of three cases. Int Ophthalmol. 2018;38(1):345-351.

12. Jung SK, Paik JS, Park GS, Yang SW. CD34 + tumours of the orbit including solitary fibrous tumours: a six-case series. BMC Ophthalmol. 2017;17(1):59.

13. Alam S, Backiavathy V, Mukherjee B, Subramanian K. A rare case of giant multicystic solitary fibrous tumor of the orbit. Orbit. 2018;37(1):69-72.

14. Vu AF, Chundury RV, Blandford AD, Perry JD. Recurrent orbital solitary fibrous tumor in a 12-year-old. Ocul Oncol Pathol. 2017;3(2):83-86.

15. Künzel J, Hainz M, Ziebart T, et al. Head and neck solitary fibrous tumors: a rare and challenging entity. Eur Arch Otorhinolaryngol. 2016;273(6):1589-1598.

16. Goodlad JR, Fletcher CD. Solitary fibrous tumour arising at unusual sites: analysis of a series. Histopathology. 1991;19(6):515-522.

17. Suster S, Nascimento AG, Miettinen M, Sickel JZ, Moran CA. Solitary fibrous tumors of soft tissue. A clinicopathologic and immunohistochemical study of 12 cases. Am J Surg Pathol. 1995;19(11):1257-1266.

18. Chan JK. Solitary fibrous tumour-everywhere, and a diagnosis in vogue. Histopathology. 1997;31(6):568-576.

19. Ganly I, Patel SG, Stambuk HE, et al. Solitary fibrous tumors of the head and neck: a clinicopathologic and radiologic review. Arch Otolaryngol Head Neck Surg. 2006;132(5):517-525.

20. Rayappa CS, McArthur PD, Gangopadhyay K, Antonius JI. Solitary fibrous tumour of the infratemporal fossa. J Laryngol Otol. 1996;110(6):594-597.

21. Sato J, Asakura K, Yokoyama Y, Satoh M. Solitary fibrous tumor of the parotid gland extending to the parapharyngeal space. Eur Arch Otorhinolaryngol. 1998;255(1):18-21.

22. Bernardini FP, de Conciliis C, Schneider S, Kersten RC, Kulwin DR Solitary fibrous tumor of the orbit: is it rare? Report of a case series and review of the literature. Ophthalmology. 2003;110(7):1442-1448.

23. Krishnakumar S, Subramanian N, Mohan ER, Mahesh L, Biswas J, Rao NA. Solitary fibrous tumor of the orbit: a clinicopathologic study of six cases with review of the literature. Surv Ophthalmol. 2003;48(5): 544-554.

24. Leoncini G, Maio V, Puccioni M, et al. Orbital solitary fibrous tumor: a case report and review of the literature. Pathol Oncol Res. 2008;14(2):213-217.

25. Tam ES, Chen EC, Nijhawan N, Harvey JT, Howarth D, Oestreicher JH. Solitary fibrous tumor of the orbit: a case series. Orbit. 2008;27(6):426-431.

26. Romer M, Bode B, Schuknecht B, Schmid S, Holzmann D. Solitary fibrous tumor of the orbit-two cases and a review of the literature. Eur Arch Otorhinolaryngol. 2005;262(2):81-88.

27. Kim HJ, Kim HJ, Kim YD, et al. Solitary fibrous tumor of the orbit: CT and MR imaging findings. AJNR Am JNeuroradiol. 2008;29(5):857-862.
28. Kim HY, Lee SY, Kang SJ, Kim HJ. Solitary fibrous tumor of the orbit: a poorly recognized orbital lesion. Acta Ophthalmol Scand. 1999;77(6):704-708.

29. Hayashi S, Kurihara H, Hirato J, Sasaki T. Solitary fibrous tumor of the orbit with extraorbital extension: case report. Neurosurgery. 2001;49(5):1241-1245.

30. Johnson TE, Onofrey CB, Ehlies FJ. Echography as a useful adjunct in the diagnosis of orbital solitary fibrous tumor. Ophthal Plast Reconstr Surg. 2003;19(1):68-74.

31. Kim TA, Brunberg JA, Pearson JP, Ross DA. Solitary fibrous tumor of the paranasal sinuses: CT and MR appearance. AJNR Am J Neuroradiol. 1996;17(9):1767-1772.

32. Dunfee BL, Sakai O, Spiegel JH, Pistey R. Solitary fibrous tumor of the buccal space. AJNR Am J Neuroradiol. 2005;26(8):2114-2116.

33. Kim HJ, Lee HK, Seo JJ, et al. MR imaging of solitary fibrous tumors in the head and neck. Korean J Radiol. 2005;6(3):136-142.

34. Meyer D, Riley F. Solitary fibrous tumor of the orbit: a clinicopathologic entity that warrants both a heightened awareness and an atraumatic surgical removal technique. Orbit. 2006;25(1):45-50.

35. Shin JH, Sung IY, Suh JH, et al. Solitary fibrous tumor in the buccal space: MR findings with pathologic correlation. AJNR Am J Neuroradiol. 2001; 22(10):1890-1892.

36. Jeong AK, Lee HK, Kim SY, Cho KJ. Solitary fibrous tumor of the parapharyngeal space: MR imaging findings. AJNR Am J Neuroradiol. 2002;23(3):473-475.

37. Tateishi U, Nishihara H, Morikawa T, Miyasaka K. Solitary fibrous tumor of the pleura: MR appearance and enhancement pattern. J Comput Assist Tomogr. 2002;26(2):174-179.

38. Furusato E, Valenzuela IA, Fanburg-Smith JC, et al. Orbital solitary fibrous tumor: encompassing terminology for hemangiopericytoma, giant cell angiofibroma, and fibrous histiocytoma of the orbit: reappraisal of 41 cases. Hum Pathol. 2011;42(1):120-128.

39. Mentzel T, Bainbridge TC, Katenkamp D. Solitary fibrous tumor: clinicopathologic, immunohistochemical, and ultrastructural analysis of 12 cases arising in soft tissues, nasal cavity and nasopharynx, urinary bladder and prostate. Virchows Arch. 1997;430(6):445-453.

40. Kanthan R, Torkian B. Recurrent solitary fibrous tumor of the pleura with malignant transformation. Arch Pathol Lab Med. 2004;128(4):460-462.

41. Suster S, Fisher C, Moran CA. Expression of bcl-2 oncoprotein in benign and malignant spindle cell tumors of soft tissue, skin, serosal surfaces, and gastrointestinal tract. Am J Surg Pathol. 1998;22(7):863-872.

42. Hsu CH, Wei YH, Peng Y, Liao SL. Orbital hemangiopericytoma in an Asian population. J Formos Med Assoc. 2014;113(6):356-563.

43. Tihan T, Viglione M, Rosenblum MK, Olivi A, Burger PC. Solitary fibrous tumors in the central nervous system. A clinicopathologic review of 18 cases and comparison to meningeal hemangiopericytomas. Arch Pathol Lab Med. 2003;127(4):432-439.

44. Carrera M, Prat J, Quintana M. Malignant solitary fibrous tumour of the orbit: report of a case with 8 years follow-up. Eye (Lond). 2001;15(Pt 1):102-104

45. Girnita L, Sahlin S, Orrego A, Seregard S. Malignant solitary fibrous tumour of the orbit. Acta Ophthalmol. 2009;87(4):464-467.

46. Polito E, Tosi GM, Toti P, Schürfeld K, Caporossi A. Orbital solitary fibrous tumor with aggressive behavior: three cases and review of the literature. Graefes Arch Clin Exp Ophthalmol. 2002;240(7):570-574.

47. Welling LC, Lynch JC, Ferreira LA, et al. Solitary fibrous tumor with intracranial invasion. Arq Neuropsiquiatr. 2009;67(3A):701-703.

48. Suzuki S. A case of malignant solitary fibrous tumor presenting with exophthalmos. Jpn J Clin Oncol. 2007;37(5):401.

49. Patel MM, Jakobiec FA, Zakka FR, et al. Intraorbital metastasis from solitary fibrous tumor. Ophthal Plast Reconstr Surg. 2013;29(3):e76-e79.

50. Woo KI, Suh YL, Kim YD. Solitary fibrous tumor of the lacrimal sac. Ophthal Plast Reconstr Surg. 1999;15(6):450-453.

51. Alexandrakis G, Johnson TE. Recurrent orbital solitary fibrous tumor in a 14-year-old girl. Am J Ophthalmol. 2000;130(3):373-376.

52. Griepentrog GJ, Harris GJ, Zambrano EV. Multiply recurrent solitary fibrous tumor of the orbit without malignant degeneration: a 45-year clinicopathologic case study. JAMA Ophthalmol. 2013;131(2):265-267. 
53. Parrozzani R, Fusetti S, Montesco C, Favero V, Midena E. Biphasic solitary fibrous tumor of the orbit with distant metastases. Int Ophthalmol. 2013;33(6):701-705.

54. Young TK, Hardy TG. Solitary fibrous tumor of the orbit with intracranial involvement. Ophthal Plast Reconstr Surg. 2011;27(3):e74-e76.

55. Inoue T, Owada Y, Watanabe Y, et al. Recurrent intrapulmonary solitary fibrous tumor with malignant transformation. Ann Thorac Surg. 2016;102(1):e43-e45.

56. Tominaga N, Kawarasaki C, Kanemoto K, et al. Recurrent solitary fibrous tumor of the pleura with malignant transformation and non-islet cell tumor-induced hypoglycemia due to paraneoplastic overexpression and secretion of high-molecular-weight insulin-like growth factor II. Intern Med. 2012;51(23):3267-3272.

57. Yoshimura Y, Sano K, Isobe K, Aoki K, Kito M, Kato H. A recurrent solitary fibrous tumor of the thigh with malignant transformation: a case report. Int J Surg Case Rep. 2016;21:111-114.
58. Manousaridis K, Stropahl G, Guthoff RF. Rezidivierender maligner solitärer fibröser Tumor der Orbita [Recurrent malignant solitary fibrous tumor of the orbit]. Ophthalmologe. 2011;108(3):260-264. German [with English abstract].

59. Wang X, Qian J, Bi Y, Ping B, Zhang R. Malignant transformation of orbital solitary fibrous tumor. Int Ophthalmol. 2013;33(3):299-303.

60. Blandamura S, Alaggio R, Bettini G, Guzzardo V, Valentini E, Bedogni A. Four cases of solitary fibrous tumour of the eye and orbit: one with sarcomatous transformation after radiotherapy and one in a 5-year-old child's eyelid. J Clin Pathol. 2014;67(3):263-267.

61. Yokoi T, Tsuzuki T, Yatabe Y, et al. Solitary fibrous tumour: significance of p53 and CD34 immunoreactivity in its malignant transformation. Histopathology. 1998;32(5):423-432.

62. Chen H, Xiao CW, Wang T, et al. Orbital solitary fibrous tumor: a clinicopathologic study of ten cases with long-term follow-up. Acta Neurochir (Wien). 2012;154(2):249-255.
Cancer Management and Research

\section{Publish your work in this journal}

Cancer Management and Research is an international, peer-reviewed open access journal focusing on cancer research and the optimal use of preventative and integrated treatment interventions to achieve improved outcomes, enhanced survival and quality of life for the cancer patient. The manuscript management system is completely online and includes
Dovepress

a very quick and fair peer-review system, which is all easy to use. Visit http://www.dovepress.com/testimonials.php to read real quotes from published authors. 